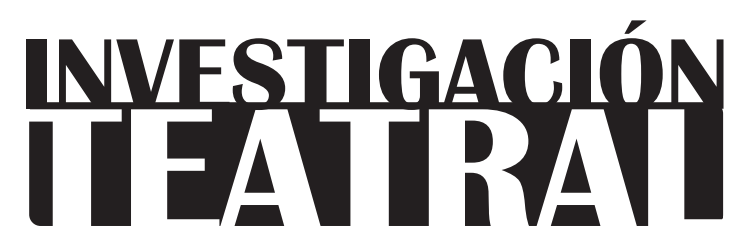

Revista de artes escénicas y performatividad

Vol. 10, Núm. 16

octubre 2019-marzo 2020

Segunda época

ISSN impreso: 1665-8728

ISSN electrónico: 2594-0953

Universidad Veracruzana

\title{
Teatro liminal, poesía y un pasado que no muere en la Plaza de Tlatelolco: Auxilio: Au Secours
}

\author{
Jacqueline E. Bixler*
}

* Virginia Tech University, Estados Unidos. e-mail: jbixler@vt.edu

Recibido: 08 de julio de 2019

Aceptado: 16 de agosto de 2019

Doi: $10.25009 /$ it.v10i16.2603 


\title{
Teatro liminal, poesía y un pasado que no muere en la Plaza de Tlatelolco: Auxilio: Au Secours
}

\section{Resumen}

En el otoño de 2018, los grupos colectivos TeatroSinParedes y Thèatre 2 L'acte montaron la pieza colaborativa francomexicana Auxilio: Au Secours, en el Centro Cultural Universitario Tlatelolco, durante el quincuagésimo aniversario del 2 de octubre de 1968. En esta pieza se combinan el teatro, la poesía, la narrativa de Roberto Bolaño y configuraciones espacio-temporales que obligan a los espectadores a abandonar su pasividad, enfrentarse con el legado del 68 y reconocer su responsabilidad en la creación del futuro de México. Incorporando las teorías de Rancière, Benjamin y otros, este artículo muestra cómo la representación de Auxilio descentraliza el 68 al desplazarse entre pasado, presente y futuro y al representar el ciclo de represión, violencia y desilusión que impide que el pasado muera y, por ende, que los mexicanos contemplen el futuro.

Palabras clave: 1968, Roberto Bolaño, Alcira Soust Scaffo, TeatroSinParedes, Thèatre 2 L'acte, México.

\section{Liminal Theatre, Poetry and a Past that Lives on in the Tlatelolco Plaza: Auxilio: Au Secours}

\begin{abstract}
In the fall of 2018, collective theatre groups TeatroSinParedes and Thèatre 2 Lacte staged a collaborative Franco-Mexican piece, Auxilio: Au Secours, in the Centro Cultural Universitario Tlatelolco as part of the fiftieth anniversary of October 2, 1968. In this performative work, theatre, poetry, the narrative of Roberto Bolaño, and temporal-spatial configurations are combined in order to force the spectators to abandon their comfortable passivity, come to grips with the legacy of 1968, and recognize their responsibility in determining Mexico's future. By incorporating the theories of Rancière, Benjamin, and others, this article shows how the creators of Auxilio decenter 1968 by moving among past, present, and future; thereby representing the cycle of repression, violence, and disillusion that keeps the past alive, and impedes Mexicans to look into the future.
\end{abstract}

Keywords: 1968, Roberto Bolaño, Alcira Soust Scaffo, TeatroSinParedes, Thèatre 2 Lacte, Mexico. 


\section{Teatro liminal, poesía y un pasado que no muere en la Plaza de Tlatelolco: Auxilio: Au Secours}

The past is never dead. It's not even past. William Faulkner, Requiem for a Nun

No hay más poesía que la acción real. Pier Paolo Passolini

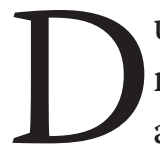
urante los últimos 50 años, más de 100 obras dramáticas han retomado el tema del movimiento estudiantil y del 2 de octubre de 1968. Con motivo del quincuagésimo aniversario de la masacre en la Plaza de Tlatelolco, la Universidad Nacional Autónoma de México (UNAM) llevó a cabo el Memorial 68 que, entre otras actividades, incluyó cuatro obras teatrales: Conmemorantes (1981, Emilio Carballido), La hecatombe (2018, Juan Tovar), Palinuro en la escalera (1977, Fernando del Paso) y A Chuchita sí la bolsearon, sí la llevaron al baile y sí le hicieron de chivo los tamales (2018, Las Reinas Chulas). ${ }^{1}$ Mien-

1 En otro estudio, que será publicado en Latin American Research Review, analizo varias farsas que se montaron dentro del marco del Memorial del 68. Además de La hecatombe, Palinuro en la escalera y $A$ Chuchita sí la bolsearon, sí la llevaron al baile y sí le hicieron de chivo los tamales, incluyo Olimpia 68 (2008, Flavio González Mello) y México 1968 (2018, David Olguín). Aunque el uso de la farsa para el tratamiento de un tema tan grave podría parecer irreverente, esta forma de expresión dramática resulta ser la más eficaz y realista en la representación de una historia nacional que, además de ser, en sí, absurda, sigue repitiéndose en un ciclo vicioso de protesta, represión, violencia e impunidad. 
tras estas obras se montaban en los teatros lejanos de la UNAM, el Centro Cultural Universitario Tlatelolco (CCUT) presentó, por su parte (y en la misma plaza en donde ocurrió la masacre), la obra Auxilio: Au Secours (2018), una colaboración escénica francomexicana entre TeatroSinParedes y Thèatre 2 L'acte. $^{2}$

A diferencia de los muchos dramaturgos y grupos que han retomado el tema de México 1968 a través de la tragedia, el drama familiar, el melodrama y la farsa, ${ }^{3}$ TeatroSinParedes y Thèatre 2 L'acte se aproximan a este incómodo e inconcluso capítulo de la historia de México con una pieza escénica-poética que sigue lo que Ileana Diéguez ha denominado como teatro liminal. Este tipo de teatro aborda "escrituras escénicas y performativas experimentales, asociadas a procesos de investigación, en los bordes de lo teatral, explorando estrategias de las artes visuales y dentro de la tradición del arte independiente, desvinculadas de proyectos institucionales u oficiales" (Escenarios 18). Otros teóricos le han dado otros nombres, como "teatro posdramático" (Hans-Thies Lehmann), "teatro expandido" (José A. Sánchez) y "teatro performativo" (Josette Féral), términos que, según Antonio Prieto Stambaugh, "sirven como paraguas para identificar una enorme variedad de experiencias contemporáneas que subvierten los binarismos teatro/performance, representación/presentación, texto/cuerpo, actor/espectador, arte/vida, público/privado, ficción/realidad" ("Memorias inquietas" 208). Así como implica el nombre del grupo mexicano, en la puesta en escena de Auxilio se derrumba no sólo la cuarta pared, sino todas las paredes. Además de una mezcla híbrida de géneros - poesía, narrativa y teatro-, esta pieza incluye varias dislocaciones espacio-temporales que obligan al espectador a establecer conexiones y, últimamente, a determinar el significado de la obra.

Lejos de obsesionarse con el tema de la memoria, de entonar las hoy desgastadas porras del 68 o de exigir la verdad y el fin de la impunidad con gritos al vacío, TeatroSinParedes y Thèatre 2 L'acte establecen como punto de partida el año 2018, desde el cual invitan al espectador a confrontar el pasado y a asomarse al futuro. El objetivo es llevar a los espectadores -que bien podrían ser hijos de los que participaron en el movimiento del 68- a abandonar teatral y políticamente su cómodo estado de pasividad y a reflexionar sobre el legado de las generaciones anteriores, sobre su propia responsabilidad vis-à-vis el pasado y sobre la necesidad de determinar de manera colectiva el futuro de México. Con una estructura

2 Además del CCUT, Auxilio se presentó en la UnAm y en el Instituto Politécnico Nacional. Así como la Plaza de Tlatelolco, estos lugares están política e históricamente cargados por haber sido sitios de intensa protesta y resistencia durante el verano de 1968 . Se supone que cada uno habrá desencadenado memorias y emociones diferentes en sus públicos respectivos.

3 Para más información sobre lo que se llama "el teatro del 68", véanse los estudios de Bixler, Guyomarch y Harmony. 
tripartita, Auxilio: Au Secours descentraliza el 68, haciendo constatar que es un pasado que no ha pasado, que sigue vivo no sólo en la memoria, sino también en el momento presente, donde la misma historia de represión y violencia se repite en un ciclo interminable. ${ }^{4}$ Las teorías de Jacques Rancière, Walter Benjamin, Ileana Diéguez, Susana Draper y Katherine Hite, entre otros, ayudan a entender el proceso de estos dos grupos para involucrar y movilizar al espectador, liberándolo así de su estado normal de pasividad y obligándolo a sentirse parte de un continuo histórico y partícipe del momento crítico actual.

En su libro 1968 Mexico: Constellations of Freedom and Democracy, Susana Draper rechaza el concepto del 68 como un momento fijo y lo reconfigura como una constelación de "conceptos, imágenes, cuerpos y memorias que emergen como maneras de seguirlo en el pensamiento, en la imagen y en un presente lejano" $(\mathrm{x}) .{ }^{5}$ Draper identifica paralelos entre el movimiento del 68 y el de \#YoSoy132 de 2012, particularmente la demanda de los estudiantes por "la reconfiguración del escenario que posibilita lo político y en el que narramos la posibilidad del cambio, la historicidad del presente en continuo diálogo con el pasado" (XIII). ${ }^{6}$ A pesar de que Draper no incluye al teatro entre los vehículos literarios que se han usado para extender y diversificar la memoria del 68, sus observaciones pueden extrapolarse a los "escenarios" literales en los que TeatroSinParedes, Teatro Ojo, Lagartijas Tiradas al Sol y otros grupos colectivos mexicanos ponen en escena esta misma constelación de conceptos, imágenes, cuerpos y memorias. Son montajes que "pronostican" el futuro del 68, crean un continuo histórico y fomentan un sentido de comunidad entre actores y público. ${ }^{7}$ TeatroSinParedes y Thèatre 2 L'acte plantean que la quincuagésima conmemoración del 68 no es el momento

4 Es importante señalar que Auxilio no es la primera intervención escénica que aborda el tema de 1968 y Tlatelolco. Como parte de la cuadragésima conmemoración, el colectivo Teatro Ojo montó iNo? en varios espacios públicos clave y durante las fechas correspondientes (e.g., el 27 de agosto en el Zócalo, el dos de octubre en la Plaza de Tlatelolco). Los miembros entablaron con los peatones un diálogo sobre el 68 con fotos, carteles, música y spots. En otra obra, S. R. E. Visitas guiadas (2007), el mismo grupo le dio al público una visita guiada por el edificio abandonado que había sido la sede de la Secretaría de Relaciones Exteriores, y desde el cual Luis Echeverría dirigió la masacre. El mismo edificio ahora pertenece a la UNAM y se conoce como el Centro Cultural Universitario Tlatelolco.

5 "[...] concepts, images, bodies, and memories that emerge as modes of continuing it in thought, in image, and in a distant present".

6 "[...] the reconfiguration of the stage that makes the political possible [and on which] we narrate the possibility of change, the historicity of the present in constant dialogue with the past".

7 En un artículo proyectado, estudio Auxilio y El pasado no se muere, ni siquiera es pasado (2018), del grupo Lagartijas Tiradas al Sol. Además de abordar el tema de México 68, las dos obras fueron montadas en el CCUT y comparten una estructura tripartita en términos temporales y espaciales. Para un breve análisis de ${ }_{i N o}$ ? (Teatro Ojo, 2008), véase Diéguez. 
para recordar y lamentar a los mártires de Tlatelolco, sino, como sugiere Katherine Hite en su libro sobre la política y el arte de la conmemoración, para "recuperar el potencial de transformar 'los significados pasados' y así movilizar el presente" (1). ${ }^{8}$

Parte fundamental de este proceso de movilizar al presente, explica Jacques Rancière, consiste en enfrentar al espectador con una reconfiguración desconcertante de la historia, para así liberarlo de su pasividad convencional. En su estudio de !No? (Teatro Ojo, 2008), otra propuesta escénica sobre el 68, Diéguez describe con mayor detalle este proceso: "[S]e construye como intervención poética que busca detonar, interrogar o provocar el tejido social y urbano, y al hacer de los espectadores participantes que reconfiguran las acciones según el grado de colaboración" (27). Esto a su vez se relaciona con la teoría de Lehmann sobre el teatro posdramático, en el que "hay más presencia que representación [...], más proceso que producto, más manifestación que significación y más impulso activo que información" (85). Finalmente, Sánchez emplea el término "teatro expandido" para describir este mismo tipo de representación híbrida que resalta su propia teatralidad y funge como intervención sociopolítica:

a través de distintas formas de interlocución [que] apelan a la noción de teatralidad y [...] describen o construyen paisajes que nos invitan a mirar. Un mirar basado en la potencialidad de la acción reflexiva, que pone de manifiesto la importancia de entender y erigir el 'nosotros' (15).

Este "nosotros" al que alude Sánchez es el público y el sentido de comunidad y de participación comunitaria que crea el teatro, que es, según Rancière, el único lugar donde el público se confronta consigo mismo como colectivo (5).

Este acto de mirar que describe Sánchez se lleva a cabo en Auxilio cuando los espectadores participan colectivamente en una visita guiada por la historia mexicana reciente y por el Centro Cultural Universitario Tlatelolco, donde se desplazan de un espacio teatral y temporal a otro. De esta manera se convierten en lo que Prieto Stambaugh denomina "espectandantes, espectadores caminantes, cuyo caminar, presencias y testimonios forma[n] parte del discurso escénico" ("El puro lugar" 131). Al grupo de veintitantos espectadores se le indica varias veces y sin palabras que se ponga de pie para ser dirigido de un espacio oscuro del CCUT a otro. $\mathrm{Al}$ no recibir instrucciones verbales, los espectadores se ven obligados a guiarse entre ellos mientras se esfuerzan por entender adónde los llevan y qué deben hacer una vez que lleguen. Esto forma parte del proceso de emancipar al espectador, como explica Rancière: "se

8 “[...] to revive the potential to transform 'past meanings' in order to mobilize the present". 
le enseña un espectáculo extraño, inusual, un enigma cuyo significado debe buscar. De esta manera se le compele a cambiar su estado de espectador pasivo por el del investigador científico o experimentador que observa fenómenos y busca sus causas" (4). ${ }^{9}$ En sus comentarios sobre el teatro mexicano del nuevo milenio, el investigador Rubén Ortiz observa que

toda aquella atención que el teatro moderno ponía en la reflexión acerca del actor y de la escena cerrada está ahora puesta del lado del espectador y del contexto. [...] Los actores no se ofrecen como personajes al servicio de una línea narrativa, sino como interventores en una secuencia escénica. [...L] os propios espectadores pueden volverse los conductores del acontecimiento mientras los actores funcionan únicamente como guías del flujo del evento (314).

Mientras los actores de Auxilio guían silenciosamente a los espectadores de un lugar/año a otro, estos experimentan una secuencia de breves escenas e imágenes incongruentes que ellos mismos necesitan reconfigurar e hilar para determinar el significado de lo que están viendo.

En su conocida tesis sobre el Angelus Novus, de Paul Klee, Walter Benjamin vincula este acto de "mirar" con la cuestión de la responsabilidad histórica. Según Benjamin, este cuadro representa la tendencia del ser humano a obsesionarse con lo peor del pasado y su renuencia a enfrentarse al futuro. No hay duda de que, en el caso de México, un detritus del pasado que obstaculiza el camino hacia el futuro es el 2 de octubre de 1968. Debido a la falta de transparencia, verdad y justicia que siguió a la masacre, a los mexicanos les ha sido imposible librarse de esta parte del pasado. Como bien se sabe, el pasado no puede ser realmente pasado hasta que haya dejado de suceder, o en este caso, hasta que deje de repetirse. Durante los últimos 50 años, el lema "el dos de octubre no se olvida" simplemente se ha consolidado con la repetición del mismo ciclo de protesta, represión, violencia e impunidad. Es precisamente por eso, explica Draper, que el 68 no es un evento aislado: "atraviesa la historia mexicana al ritmo de la movilización y de la constante represión mantenida por el Estado" (193). ${ }^{10}$ El ejemplo más notable ocurrió el 26 de septiembre de 2014 con la desaparición forzada de los 43 estudiantes de Ayotzinapa, un episodio que hizo aún más insuperable ese montón de escombros que, según Benjamin, le impide al Ángel de la Historia dejar de mirar atrás para dirigir su mirada hacia el futuro.

9 " $[. .$.$] is shown a strange, unusual spectacle, a mystery whose meaning he must seek out. He will thus be$ compelled to exchange the position of passive spectator for that of scientific investigator o experimenter, who observes phenomena and searches for their causes".

10 "[it] traverses Mexican history to the rhythm of mobilization and to the constant of state repression". 
El objetivo de esta coproducción francomexicana de TeatroSinParedes y Thèatre 2 Lacte no es rememorar o reconstruir los eventos del 68, sino utilizar aquel año tumultuoso como contexto y punto de partida. ${ }^{11}$ Como explica Benjamin: "Articular históricamente el pasado no significa reconocerlo 'tal como era' (Ranke). Significa abrazarse a su memoria en el momento en que nos indique que está en peligro" (257) ${ }^{12}$ Está de más decir que México se encuentra hoy en este momento de peligro, con un nuevo presidente y partido en el poder, y con un nivel sin precedentes de violencia, corrupción e inseguridad.

Auxilio aborda el pasado, el presente y el futuro de México en tres partes independientes -"El cagadero", "La púa de la bisagra" y "Fragmentos del amuleto roto"-, cada una creada respectivamente por los siguientes pares de dramaturgo y director: Serge Pey y Michel Mathieu; Sergio Felipe López Vigueras y David Psalmon, así como Ángel Hernández y Sébastien Lange. Como suele ser el caso con las intervenciones escénicas de grupos colectivos independientes, el montaje de Auxilio tuvo lugar en un lugar históricamente cargado -el Centro Cultural Universitario Tlatelolco-, un edificio imponente que mira desde arriba a la Plaza de Tlatelolco y que ocupa el edificio que anteriormente fue la Secretaría de Relaciones Exteriores (desde donde se dio la orden de terminar a toda costa con el movimiento estudiantil). ${ }^{13}$ El uso de la Plaza de Tlatelolco como escenario se relaciona con la noción de topofilia propuesta por Gaston Bachelard: "aquel espacio frente al cual no podemos permanecer indiferentes, dada su gran carga de significación” (22). Cada parte del espectáculo corresponde a otro espacio del CCUT y a otro año -1968, 2018 y 2068-. A pesar de que se trata de una estructura estrictamente tripartita, las distintas partes se mantienen

11 TeatroSinParedes es un colectivo teatral y editorial dirigido por David Psalmon, quien nació en París en 1973; ha vivido y trabajado en México desde 2000. El grupo fue fundado en 2001. Entre sus espectáculos más emblemáticos se encuentran Emigrados, La inauguración, La excepción y la regla, UTOPYA, Humboldt y Last Man Standing.

A diferencia de otras producciones de TSP, Auxilio: Au Secours es producto de una colaboración entre directores, dramaturgos y actores mexicanos y franceses. Además de los montajes que se hicieron en México, la obra tuvo representaciones en Francia, donde en mayo 1968 empezaron las revueltas estudiantiles que llegarían después a México. En el programa de mano, TeatroSinParedes y Thèatre 2 L'acte reconocen que "Si el mayo parisino fue globalmente pacífico, el octubre mexicano terminó en un mar de sangre". La obra se inspira del encierro de Alcira Soust Scaffo, un hecho histórico que les sirve, según ellos, "como punto de partida de un mural poético fragmentado e interrogante sobre la ola contestataria que oscila entre dos continentes".

12 "To articulate the past historically does not mean to recognize it 'the way it really was' (Ranke). It means to seize hold of a memory as it flashes up at a moment of danger".

13 Esta descripción de Auxilio se basa en el montaje que vi el 15 de noviembre de 2018 en el Centro Cultural Universitario Tlatelolco. 
vinculadas a través de la protagonista Auxilio Lacouture, la omnipresencia de un inodoro, referencias intertextuales a la narrativa de Roberto Bolaño y la poesía como tema y como vehículo discursivo dramático. Otra constante es el uso del coro. Si bien cambia de aspecto físico, papel dramático y hasta de género, el coro establece y mantiene un contacto directo con el público, a la vez que sirve como una voz colectiva que hace hincapié en el fuerte compromiso político de estos dos grupos colectivos.

Aunque sin saberlo, cuando el público entra al CCUT, el coro de Auxilio (que consta de cuatro personas) ya se encuentra presente. De hecho, el pequeño coro pone en marcha el "espectáculo extraño, inusual, un enigma cuyo significado debe buscar", que describe Rancière, con lo que se podría llamar un prólogo. Consiste en una voz en off que prepara al espectador para las subsecuentes interacciones con los actores. Mientras el público -que se limita a unas veinte personas- está en una antesala esperando entrar a lo que parece que será el espacio de la actuación, unas personas desaliñadas se acercan y miran al grupo fijamente, sin palabras y sin expresión facial. Incomodados por su proximidad física e inseguros de sus motivos (¿serán locos?, ¿vagabundos?), a los espectadores les resulta imposible esquivar su mirada penetrante e incesante. Poco después, alguien indica a los presentes, sin palabras, que deben salir del edificio y sentarse en unos fríos peldaños de piedra. Al llegar a este espacio, el espectador se sorprende de encontrar y de ver que esos mismos andrajosos forman parte del reparto. Durante la primera parte de la puesta, "El cagadero", los mismos sirven de coro durante el largo monólogo de la protagonista Auxilio, a la vez que representan los fantasmas de los que cayeron el 2 de octubre en la Plaza de Tlatelolco, que está a la vista de la pequeña explanada que sirve de espacio escénico.

Los que conocen las novelas de Roberto Bolaño van a reconocer a Auxilio como uno de los personajes de Los detectives salvajes (1998) y 2666 (2004) y como la protagonista de Amuleto (1999). Ella es una mezcla de persona real y leyenda urbana, de quien se sabe relativamente poco, fuera del hecho de que su verdadero nombre no era el que usa Bolaño -Auxilio Lacoutoure-, sino Alcira Soust Scaffo. ${ }^{14}$ También se sabe que era una uruguaya

14 Esta no es la primera obra dramática que se centra en la figura de Alcira Soust Scaffo. En 2008, Antonio Algarra montó en el Teatro La Capilla el unipersonal Alcira o la poesía en armas, donde Verónica Langer hizo el papel de Alcira. En una reseña del montaje, Bruno Bert subraya la importancia de Soust como un símbolo de resistencia: "Se volvió un poco el símbolo del 'resistir', con su aura de poesía, de idealismo y también de desequilibrio frente a una realidad que encarnaba la represión y la muerte” (párrafo 2). El interés en ella ha seguido creciendo durante los últimos años, particularmente desde la publicación de Amuleto en 1999. Como parte del Memorial 68 de 2018, el Museo Universitario de Arte Contemporáneo (MUAC) dedicó a su memoria toda una exposición, "Escribir poesía, ¿vivir dónde?". Al mismo tiempo, en el Festival Vértice organizado por la UNAM, se montó Luciérnaga, una ópera multimedia basada en las experiencias de Soust. Finalmente, se ha dedicado una página en Facebook a Alcira Soust Scaffo. 
indocumentada que limpiaba la casa de dos poetas exiliados de España y que andaba mucho en la UNAM, repartiendo poemas y haciendo mandados para los que trabajaban en la Torre de Humanidades. Aunque ella misma era poeta, Alcira se conoce más como la mujer que se quedó atrapada en un baño durante la ocupación militar de la UNAM. Y, también, gracias a la novela Amuleto, se le ha llegado a conocer como promotora y ferviente defensora de los jóvenes poetas mexicanos, muchos de ellos estudiantes en la UNAM. Entre estos jóvenes se encontraba el entonces adolescente Roberto Bolaño, quien en 1968 acababa de llegar de Chile con su familia.

Cuando el ejército ocupó la UNAM y detuvo a numerosos estudiantes y profesores el 18 de septiembre, Auxilio/Alcira estaba en el baño, donde se quedó encerrada y aterrada hasta el primero de octubre, cuando las tropas desalojaron la universidad. A lo largo de la ocupación, Alcira nutrió su espíritu con un libro de poesía y su cuerpo con agua y papel higiénico. De los años subsecuentes sólo se sabe que sufrió de mala salud física y mental y que, en 1988, volvió a Uruguay, donde murió nueve años después. Con el pasar de los años, la publicación de Amuleto y el reconocimiento crítico de la narrativa de Bolaño, Auxilio/Alcira ha llegado a tener cierta fama como heroína local; un espíritu libre y valiente, si bien excéntrico, que defendía hasta la locura a los jóvenes poetas y a la poesía misma como forma de resistencia.

Las únicas cosas que acompañan a Auxilio en el pequeño escenario detrás del CCUT son un inodoro, varios rollos de papel higiénico y una serie de pantallas blancas que ella va embadurnando con pintura negra y roja. La rodean los ya mencionados zombis, que de vez en cuando interrumpen el largo monólogo de ella con sus voces monótonas. Todo el discurso verbal de esta parte se comunica en verso libre, lo que no sorprende, ya que la poesía era la sustancia básica de la vida de Auxilio/Alcira tanto antes como después de su encierro en el baño. También era el género literario predilecto de Bolaño durante su juventud. Mayormente conocido por sus obras narrativas, Bolaño también fue un poeta prolífico. ${ }^{15}$ La poesía tersa y cruda proferida por Auxilio y su coro de fantasmas es bastante similar a la poesía infrarrealista que Bolaño y sus compañeros creaban durante los años 60 y 70. Roberto Ontiveros explica que "Bolaño era antes que nada un poeta. A los 23 años, desgreñado y llevando anteojos de aviador, leyó de su manifiesto 'Déjenlo todo nuevamente', en el que invocó a sus prójimos a tomar la calle y entablar un verdadero encuentro, inaugurando así el movimiento infrarrealista, inspirado por los dadaístas" (párrafo 7 ). ${ }^{16}$ La poesía de Auxilio hace eco de

15 Prueba de su prolífica producción poética es Poesía reunida, publicada en 2019 por Alfaguara. Las 627 páginas incluyen todos los poemas de Bolaño.

16 "Bolaño was a poet first. At 23, wild-haired and wearing aviator goggles, he read from his manifesto, Leave It All Again, which challenged poets to take to the road [...] and engage in actual encounter, inaugurating the dada-inspired movement Infrarealism". 
los versos de Bolaño y sus prójimos con su lenguaje simple y crudo, su predilección por la metáfora inusual y su postura rebelde frente a las autoridades y todo lo oficial.

Entre las imágenes visuales, la que da más cohesión y coherencia a las recitaciones poéticas de Auxilio y el coro de zombis es el inodoro, el que ocupa el centro del escenario, donde representa "un labio blanco", la boca en la que caga Auxilio y desde la cual fluye la poesía, el hoyo negro en el que desaparece la mierda de la historia y la memoria de los que han muerto -"Mi camarada que murió en Tlatelolco/ se ha convertido en un cagadero"- ${ }^{17}$ En efecto, quiero decir que casi todo lo que dice Auxilio se relaciona de alguna manera con el inodoro y el acto de defecar. Más allá de su polivalencia figurativa, el cagadero sirve como un ancla temporal cuando Auxilio, en su delirio, trata de marcar los días de su encerramiento:

Hace 11 días ya que estoy en el cagadero

lo único que hago es orinar.

Como no como nada

ya no cago.

Voy a quedarme en este cagadero

durante siglos.

Con esta mezcla de lo poético y lo escatológico, metáfora y excremento, Auxilio expresa la desesperación y el horror de su encierro, a la vez que establece la importancia de la poesía en términos de su propia sobrevivencia y la de la raza humana, cuyo futuro, según ella, depende de la poesía: "Tenemos que inventar un poema nuevo para inventar un hombre nuevo".

El discurso de Auxilio se vuelve menos racional y a la vez más relacional hacia el final de "El cagadero", cuando profiere una larga serie de declaraciones que comienzan con las palabras "cara a cara":

Cara a cara.

El discurso sobre la servidumbre voluntaria de La Boétie ante el traidor permanente de cualquier administración tomada al azar en Francia. cara a cara El cráneo abierto de una flor en Tijuana y una silla eléctrica. cara a cara Un poema bretón o vasco ante el sistema penitenciario francés.

Cara a cara.

17 Es importante advertir que los textos dramáticos que los miembros de TeatroSinParedes generosamente compartieron conmigo se limitan al discurso verbal. Ya que me llegaron por separado, y están inéditos y sujetos a cambios, no incluyo el número de página para los pasajes citados. 
INVESTIGACIÓNTEATRAL

Revista de artes escénicas y performatividad

Vol. 10, Núm. 16

octubre 2019-marzo 2020
Teatro liminal, poesía y un pasado que no muere en la Plaza de Tlatelolco

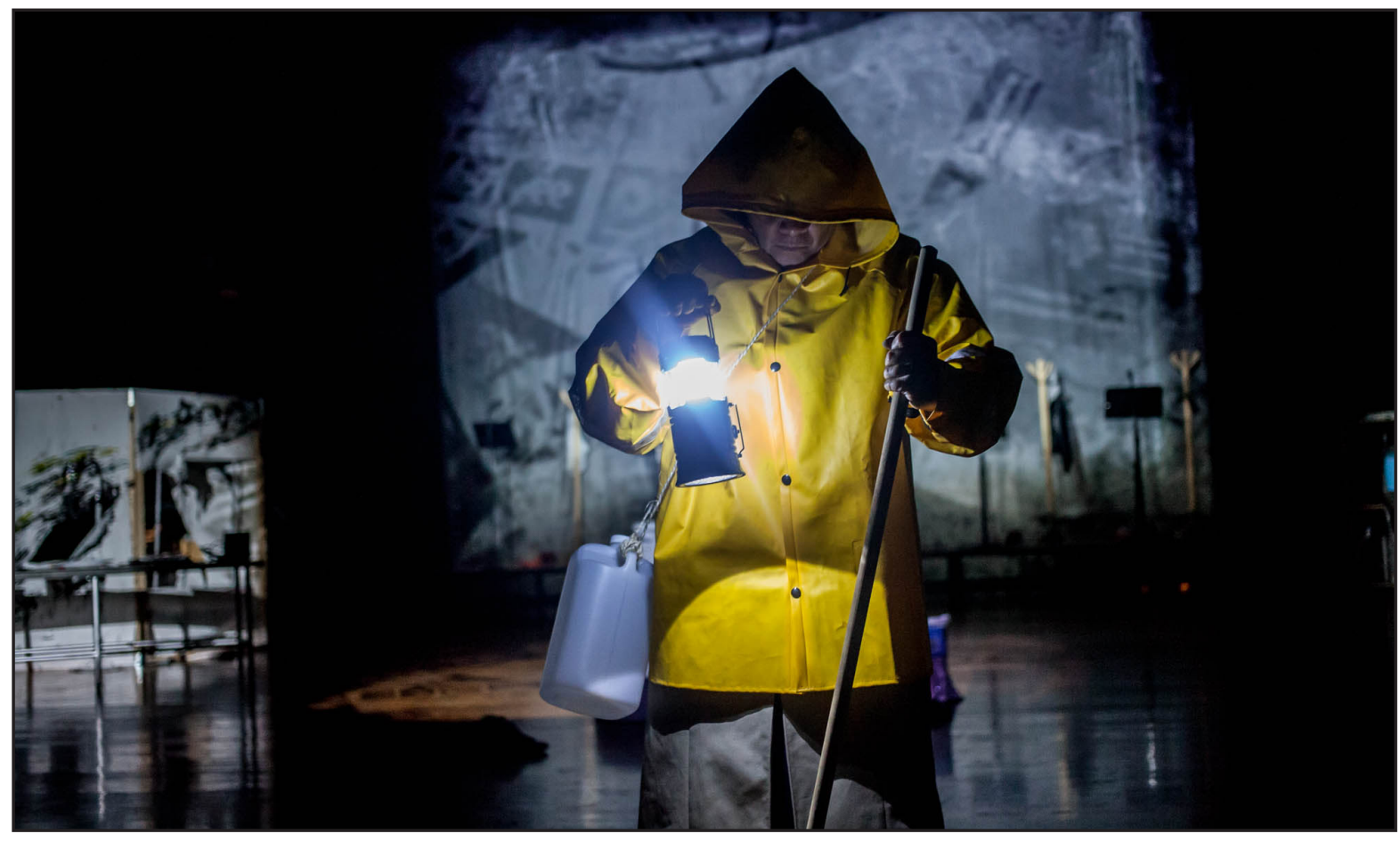

Auxilio. Zacatenco, Ciudad de México, 2018. Fotografía de Héctor Cruz Juárez.

Frente a la yuxtaposición forzada de objetos tan incongruentes, el espectador se siente obligado a relacionarlos, a buscar las conexiones. Asimismo, al referirse a fenómenos históricos de otros países, los creadores trascienden las fronteras de México y subrayan el hecho de que ni el 68 ni la violencia -tanto la de aquel año como la de hoy- se limitan a un solo país.

Después de varios minutos de "cagar" versos prosaicos, Auxilio intempestivamente deja de hablar. Sin indicio de que esta primera parte de la obra ha terminado, los espectadores se quedan sentados en la oscuridad, donde, confundidos y congelados, observan a su lado a unos hombres que llevan impermeables amarillos, botas y cubetas. Mientras remueven el contenido de la cubeta con un palo, murmuran las palabras "rascar hasta encontrar algo", lo que sugiere que buscan los restos de algo/alguien a la vez que nos prepara para la desaparición forzada que tendrá lugar en la segunda parte de la obra. En seguida, estos seres ominosos extienden las cubetas al público, invitándolo a ayudar en la búsqueda para, posteriormente y aún sin decir nada, dirigir a los confundidos espectadores al vestíbulo del CCUT.

La segunda parte, "La púa de la bisagra”, es la única que se podría llamar realista. Consiste en dos escenas que se presentan al revés y cuyo protagonista es un joven poeta y activista de nombre Bernardo. En la primera escena, el público está sentado en una sala 
INVESTIGACIÓNTEATRAL

Revista de artes escénicas y performatividad

Vol. 10, Núm. 16

octubre 2019-marzo 2020
Teatro liminal, poesía y un pasado que no muere en la Plaza de Tlatelolco

Jacqueline E. Bixler

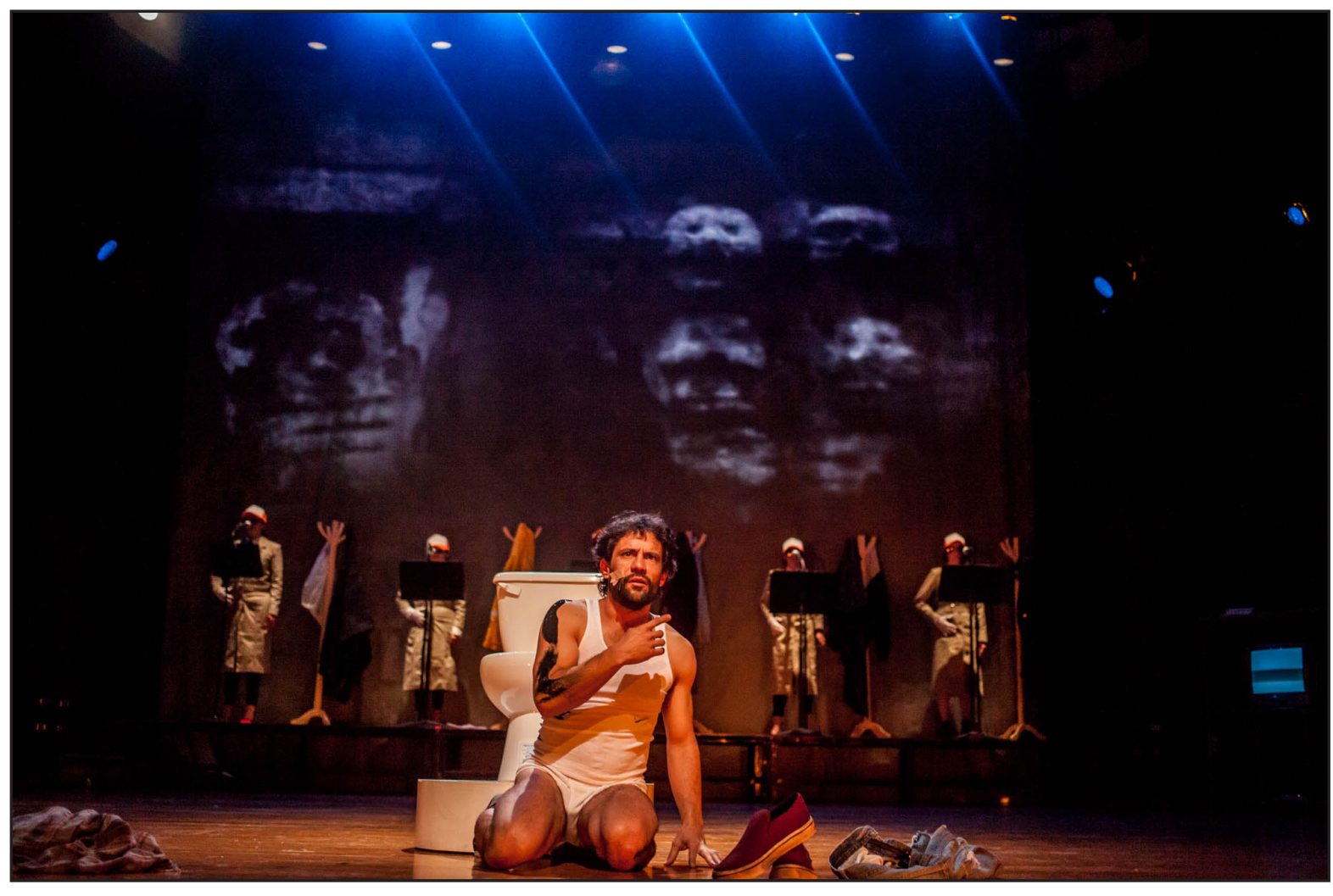

Auxilio. Zacatenco, Ciudad de México, 2018. Fotografía de Héctor Cruz Juárez.

abierta que forma parte del vestíbulo del CCUT. A un lado, hay una mesa quirúrgica llena de instrumentos y un hombre que los va escogiendo para torturar a Bernardo, quien se niega a dar información sobre sus compañeros. Al fondo del escenario hay una fila de actores vestidos de manera idéntica: uniforme militar, guantes de látex y grandes lentes oscuros. Caracterizados colectivamente como "Objetivo", estas figuras funestas (como los zombis de la primera parte) sirven de coro, describiendo bruscamente los métodos de tortura a los que el hombre está sometiendo a Bernardo. La narración de la tortura se hace en pasado, mientras otra voz llamada "Conciencia" comunica su duración e intensidad repitiendo palabras como “¿Cuánto tiempo?” y "Vueltas”:

Bernardo: Alzaste la mirada.

Torturador: ¿No me vas a decir tu nombre Bernardo?

Objetivo: Muy despacio...

Bernardo: Uno de ellos abría una lata grande de chiles. 
Torturador: ¿No me vas a decir los nombres del francés o de la maestra?

Bernardo: Viste cómo hundió la macana en la lata de chiles.

Conciencia: ¿Cuánto tiempo?

Bernardo: Revolvió lentamente.

Objetivo: Con delicadeza.

Todo se dice sin inflexión, excepto la frase incongruente "Con delicadeza", que repite melodiosamente el coro de agentes y que vuelve todavía más perturbadora la tortura y lo que parece ser el esfuerzo de las autoridades por trivializar o minimizarla.

Tras esta larga e incómoda escena de tortura, el público es dirigido a otro espacio de la sala. Aquí se ha creado un escenario que incluye la sala, el comedor y la cocina de una casa de clase media, y donde una mujer mayor prepara sopa. La presencia inmediata de Bernardo sorprende e implica que esta escena precede a la escena de tortura que el público acaba de ver. Aún más sorprendente es la presencia de varias laptops, lo que lleva al público a entender que esa misma tortura no ocurrió en 1968, sino en el presente, es decir, en 2018, y que el único "crimen" que cometió Bernardo fue el de escribir poesía. Otro factor que transporta al público a la actualidad y que funde la realidad mexicana con la ficción es el hecho de que los actores se interpretan a sí mismos, incluyendo al director David Psalmon, quien interpreta a un profesor francés que ha venido a la UNAM a impartir un seminario sobre el 68 y quien tiene como estudiante a Bernardo.

Cincuenta años después del encierro de Auxilio, los estudiantes de David igualmente consideran a la poesía como la única forma legítima de resistencia activa. En esta escena, Miriam, la hermana de Bernardo, hackea el sistema público y transmite por los altavoces de la calle uno de los poemas disidentes de su hermano. ${ }^{18}$ Juntos celebran este pequeño acto de rebelión hasta que el comunicado se vuelve viral y se dan cuenta del peligro que corren. Al final de la escena, toman las computadoras portátiles y huyen, a excepción de Bernardo, quien se queda para limpiar la computadora de escritorio y, como ya se sabe, caer en manos de las autoridades que lo torturan. A pesar de que en esta parte no se hace ninguna referencia explícita a Auxilio, ni a su encerramiento, el inodoro (que ocupa el centro del escenario) evoca a la poetisa cautiva. El uso del realismo en "La púa de la bisagra" efectivamente sirve de gozne entre el discurso figurativo de "El cagadero" y el ambiente surrealista de "Fragmentos del amuleto roto", y también hace que el espectador sienta, visceralmente, el choque aterrador de la ficción con la realidad de la vida cotidiana actual.

18 Aunque no se ha comprobado, se dice que Alcira Soust puso, en los altoparlantes de la radio comunitaria, momentos antes de que llegaran las tropas militares, un disco en el que el poeta León Felipe recitaba poemas contestatarios. 
INVESTIGACIÓNTEATRAL

Revista de artes escénicas y performatividad

Vol. 10, Núm. 16

octubre 2019-marzo 2020
Teatro liminal, poesía y un pasado que no muere en la Plaza de Tlatelolco

Jacqueline E. Bixler

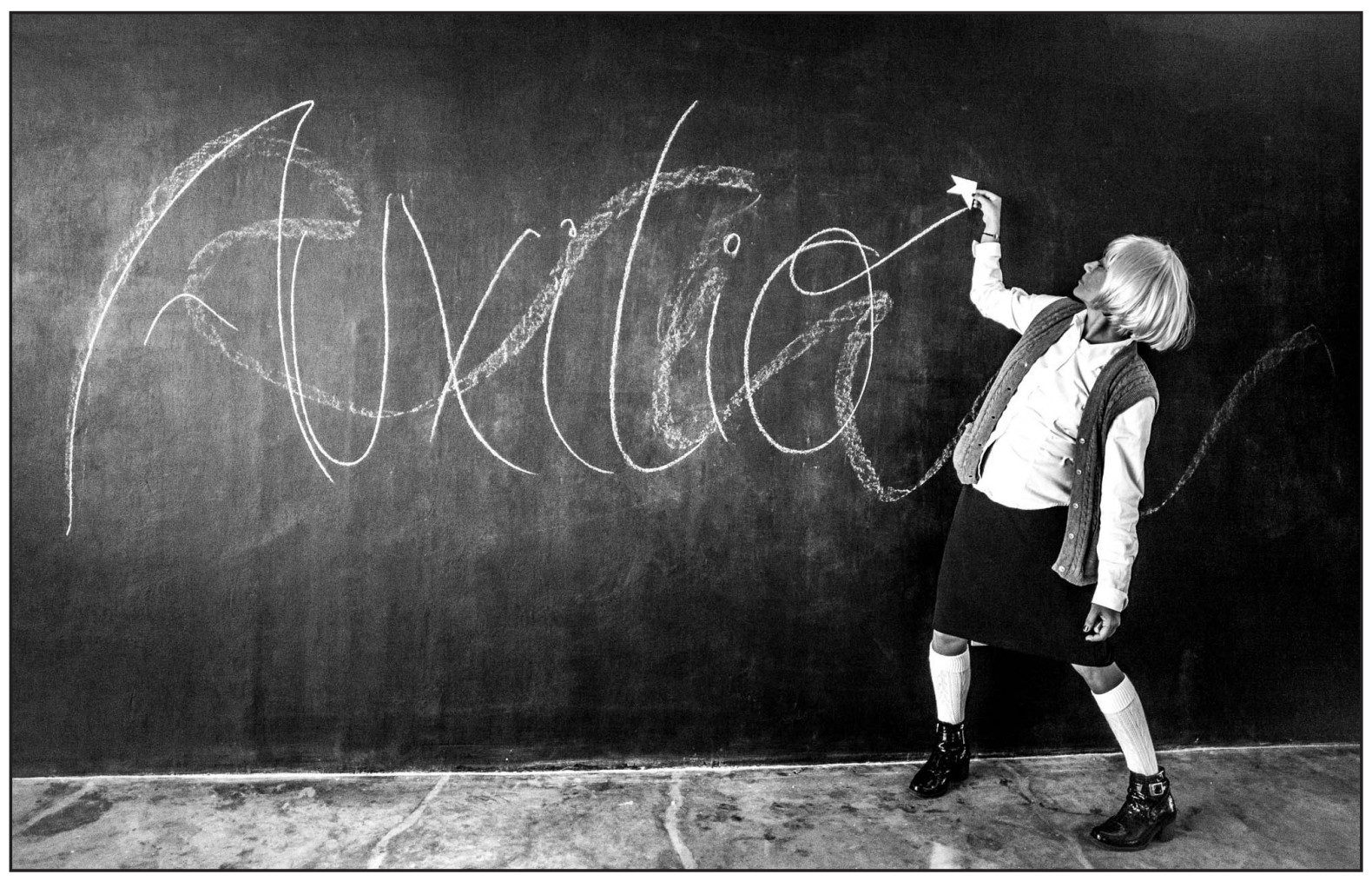

Auxilio. Zacatenco, Ciudad de México, 2018. Fotografía de Héctor Cruz Juárez.

La tercera parte de Auxilio, "Fragmentos del amuleto roto", es la que más se ahínca en la narrativa de Bolaño y, al mismo tiempo, la más difícil de desentrañar. Una línea temporal que se extiende en el suelo del vestíbulo - que el espectador fácilmente podría pasar por alto- indica que "Fragmentos" tiene lugar en 2068. ${ }^{19}$ De nuevo, el público es guiado silenciosamente a otro espacio del CCUT, que simula a una caja negra de techo alto, en donde el inodoro ocupa nuevamente el centro del escenario. Desde allí Auxilio se dirige al público, mientras que a un lado hay un grupo de músicos vestidos de cuero negro que intervienen de vez en cuando, tocando una música rock ensordecedora. Mientras tanto, los coros de zombis y agentes policiales han sido sustituidos por un grupo de colegialas idénticas, todas vestidas con un uniforme escolar de falda corta, largos calcetines blancos y una corta peluca plateada.

19 Es importante notar que esta línea temporal es la única pista que se da sobre el contexto temporal de esta tercera parte. Después de la obra, varios espectadores comentaron que no habían visto la línea y que, por lo tanto, no habían entendido que "Fragmentos" se situaba en el año 2068. 
En cada uno de los cinco momentos escénicos de "Fragmentos del amuleto roto" se oyen de nuevo ecos de Bolaño, por su lenguaje terso y la narración de encuentros entre Auxilio y otras personas -o reales o imaginadas por ella-. El título de esta parte se refiere a su novela Amuleto y también a las memorias de Tlatelolco, o lo que Auxilio llama los fragmentos que "desde 1968, no han dejado de sonar". El primer fragmento, "Decálogo", es un manifiesto en defensa de la poesía. Auxilio proclama diez frases largas, cada una comenzando con "Creo en la poesía como.... Con esta cadena de símiles, ella forja asociaciones, por ejemplo, entre la poesía y la rebelión, la poesía y la intimidad de un inodoro, la poesía y las huellas indelebles de generaciones anteriores. En una instancia, describe la poesía como "un cuartel clandestino para acumular miradas, como una convocatoria anónima de la memoria compartida". Esta imagen del cuartel clandestino se extiende a la caja negra desde la cual el espectador, incómoda y silenciosamente, comparte memorias y miradas con los desconocidos que lo rodean en la penumbra. La mirada es la misma que, según Sánchez, "pone de manifiesto la importancia de entender y erigir el 'nosotros"' (15). Aunque los espectadores no hablan entre sí en ningún momento de la obra, experimentan de manera colectiva la incomodidad y la inquietud producidas por la oscuridad y ese mismo silencio.

En el segundo fragmento, "Itinerarios", los actores siguen con esta forma críptica de dirigirse al público, pronunciando lacónicamente una serie de pasajes breves en donde cada uno es introducido por una frase que identifica al hablante, así como lo que él o ella hace mientras habla. Esto se observa, por ejemplo, en "Dos hombres mirando desde la acera contraria", "Militar encendiendo un cigarrillo" y "Madre con lentes oscuros, mirando hacia la Plaza de las Tres Culturas". Entre la penumbra de la caja negra, estas voces incorpóreas narran de manera casi telegráfica la atmósfera tensa y polarizada que reinaba en México durante y después del verano de 1968. En el tercer fragmento, "Esquema de pensamiento simultáneo", las mismas voces descorporeizadas hacen referencias a Auxilio de Amuleto y lo poco que se sabe de su vida. Se narran los pensamientos de los que conocieron a Auxilio y que, sin saber la razón de su ausencia, la resienten: Bolaño se preocupa de los libros que le prestó; la poeta Lilian Serpas se obsesiona con la idea de que Auxilio pudo haber dormido con su hijo, y el poeta español León Felipe se molesta porque no ha venido a limpiar su estudio.

El cuarto fragmento, "Presentación con vida de aquella tarde", se basa también en Amuleto. Entre el hambre y el delirio, Auxilio pierde toda conciencia del tiempo y reflexiona sobre y desde el futuro:

Imaginamos caminar Tlatelolco

cincuenta años después

y la ciudad no era muy distinta

nada había cambiado demasiado. 
Esta proyección del porvenir lleva al último fragmento, "Elena lee la mano de Auxilio". Aquí las voces de Elena (presumiblemente Elena Poniatowska) y Auxilio se alternan mientras lamentan que no haya cambiado nada durante tantos años. ${ }^{20}$

Si bien el texto de "Fragmentos del amuleto roto" se limita al discurso verbal, la representación escénica de esta parte consiste en un asalto visual y auditivo al espectador. Las palabras de Auxilio y los demás apenas se oyen contra un fondo de videos, proyecciones y música rock. Al final de cuentas, entre el revuelo y el ruido, no queda claro cuál es el objetivo del director o del dramaturgo en esta parte. El mensaje -si es que hay- que ellos proponen comunicar sobre el futuro de México se pierde entre estas Lolitas de peluca plateada, desgreñados músicos de rock y cuerpos envueltos en papel higiénico. Como observa el crítico Juan Carlos Araujo, "El resultado es fascinante a nivel visual, su plástica arrebatadora a momentos. No obstante, su contundencia no tan efectiva dada la sobrecomplejidad con que se ha desarrollado la poética" (párrafo 8). En lugar de ofrecer una conclusión, las últimas palabras pronunciadas por los actores simplemente ofrecen otro comienzo:

Elena: Ahora ellos han abierto la puerta.

Auxilio: Sí, la han abierto. Y ahora es esto lo que encontrarán aquí...

La intención es que lo que quede detrás de aquella puerta sean esos fragmentos que, como dice Auxilio, repican como campanas, puesto que "desde 1968, no han dejado de sonar dentro del mismo, interminable poema que antes de morir, vuelve a comenzar siempre, otra vez". Si el 2018 que se presenta en "La púa de la bisagra" es desolador, el 2068 con que termina la obra es todavía más negro y aterrador con su música ensordecedora, su inodoro cubierto de palabras ilegibles y con su amuleto despedazado, incapaz de cumplir con su función de proteger contra el mal y el peligro.

Después de esta conclusión inconclusa, los espectadores se quedan en la oscuridad y sin saber qué hacer, hasta que alguien les indica, siempre sin palabras, que deben salir de la caja negra y volver a la explanada exterior donde todo comenzó. Dos letreros les invitan a entrar en dos tiendas de campaña para dejar un testimonio, ya sea por escrito o en video. Los mismos letreros explican que estos comentarios escritos y grabados se pondrán

20 Aunque Poniatowska no conoció a Soust hasta 1974, en el funeral de Rosario Castellanos (ver "Otras voces"), la uruguaya aparece en La noche de Tlatelolco a través de la voz de Carolina Pérez Cicero, quien cuenta: "Durante los quince días de la ocupación de CU por el ejército se quedó encerrada en un baño de la Universidad una muchacha: Alcira. Se aterró. No pudo escapar o no quiso. Al ver a los soldados, lo primero que se le ocurrió fue encerrarse con llave. Fue horrible. Uno de los empleados que hacen la limpieza la encontró medio muerta, tirada en el mosaico del baño. ¡Quince días después!" (71). 
en una cápsula del tiempo que no se abrirá hasta el 2068. También se invita al público a degustar la sopa que se preparó durante la segunda parte de la función, un ejemplo por excelencia de lo que propone Jorge Dubatti como "convivio", ese sentido de comunidad tan único que el teatro crea entre los actores y el público, así como entre los mismos espectadores (El convivio teatral 46).

Aunque las tres partes de Auxilio difieren entre sí en términos de marco temporal y espacio escénico, también se mantienen vinculadas a través de la persistente imagen de Auxilio, las referencias a las obras de Bolaño, el uso de la poesía como arma y acto de resistencia, el inodoro omnipresente, así como el tono de denuncia que suena a la largo de la obra. Bolaño, Auxilio y Bernardo le recuerdan al público que el poder reside dentro del individuo y en su activa resistencia en contra de la opresión, una resistencia que, en este caso, se expresa por medio de la poesía. Como proclama Auxilio, "La poesía es un trabajo revolucionario/ como la revolución es un trabajo de poesía". Bernardo expresa la misma idea cuando sugiere que el futuro depende de la revolución y de la expresión creativa:

Tenemos que invadir la vida de poesía, de belleza, de arte. Así podremos incidir en la vida cotidiana a largo plazo y generar un cambio profundo, derivado de escuchar, diariamente y en distintos momentos, algo que no debería estar ahí: es la flor que crece en la grieta en el concreto.

Bolaño y sus prójimos infrarrealistas eran seguidores del poeta, dramaturgo y director italiano Pier Paolo Pasolini, para quien la poesía era la única forma de expresión que combinaba la belleza con un fuerte compromiso político. Explica Sánchez:

Lo que Pasolini propuso es que la poesía sea acción y que la acción sea poesía. Y esto no implica renunciar a la invención poética, sino más bien todo lo contrario, afirmar la invención poética en un compromiso con la acción. [...] Él se mantuvo en una tensión fuerte... entre la defensa de la poesía, la defensa del arte o la relación ineludible del arte con la belleza, con la emoción, con lo insólito, con el asombro ante la realidad, por una parte, y, por otra, el reconocimiento de una realidad social y política implacable y gris que demandaba respuestas (37).

En Auxilio, la acción disidente se convierte en acción poética y viceversa cuando Miriam hackea los altavoces públicos para compartir con toda la metrópolis un poema de Bernardo. Así como Alcira Soust, Passolini y Bolaño, TeatroSinParedes y Thèatre 2 L'acte recurren al lenguaje figurativo para decir lo indecible y para resignificar lo que con los años se ha vuelto cliché: 
INVESTIGACIÓNTEATRAL

Revista de artes escénicas y performatividad

Vol. 10, Núm. 16

octubre 2019-marzo 2020
Teatro liminal, poesía y un pasado que no muere en la Plaza de Tlatelolco

Jacqueline E. Bixler

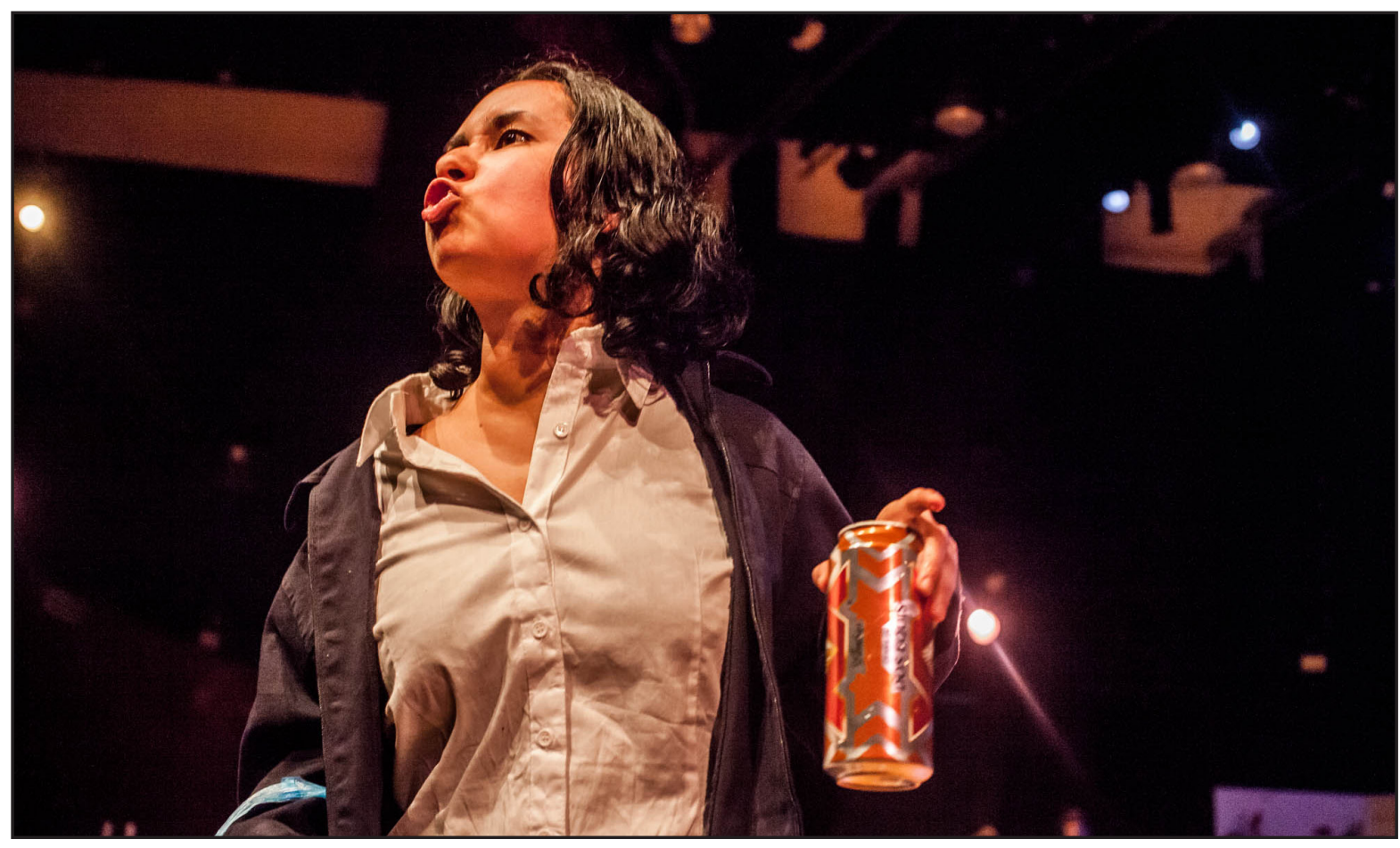

Auxilio. Zacatenco, Ciudad de México, 2018. Fotografía de Héctor Cruz Juárez.

Bernardo.- Eso es... Poesía. Palabras que digan lo otro.

Beatriz.- Es Arte: resignificar medios y mensajes.

La imagen que ofrece Bernardo, de la flor que brota desde la grieta en el concreto, es un ejemplo por excelencia de lo que Rancière llama "la imagen pensativa", una imagen que "señala la existencia de una zona de indeterminación entre el pensar y el no pensar, la acción y la pasividad, y también entre el arte y el no-arte". ${ }^{21}$ Este tipo de imagen indeterminada capta la tensión entre lo estético y lo político, la libertad y la represión, una tensión que perdura a lo largo de la puesta escénica de Auxilio y que permanece en el espectador después de que termina la obra. A nivel más amplio, las palabras de Bernardo y Beatriz se extienden a la obra misma, en la que se resignifica el 68 a través del discurso poético y la historia de una mujer poca conocida que veía en la poesía la única forma de salvación y el único camino hacia el futuro.

21 "[...] signal the existence of a zone of indeterminacy between thought and non-thought, activity and passivity, but also between art and non-art" (102). 


\section{Conclusiones}

Lo que convierte a esta obra en teatro (en contraposición con el drama escrito en verso libre) es la presencia de los espectadores, a quienes se les pide andar, mirar, reflejar y, sobre todo, reflexionar sobre cómo podría ser el futuro de México si ellos optan por no movilizarse. La obra los lleva al pasado y a la historia de Alcira Soust, para luego devolverlos al presente y hacerles entender que las cosas no han cambiado desde 1968 y que no van a cambiar a menos que ellos mismos se vuelvan partícipes en la creación de un futuro menos sombrío para México. Como dice Beatriz, colaboradora de Bernardo, le queda a la generación actual tomar acción: "[...] se contagia la necesidad de pasar a la acción. Es como si esos jóvenes de la marcha del silencio voltearan a vernos, desde el 68, y nos preguntaran: ¿Y tú? ¿Qué estás haciendo tú?". La pregunta va dirigida al público, quien queda con la responsabilidad de terminar con la apatía producida por tanta desilusión, tanta mentira, tanta repetición. Estos dos grupos de artivistas mexicanos y franceses expresan su desdén tanto a quienes pasan por alto el pasado, a fin de conservar su vida cómoda y despreocupada, como a quienes estudian el pasado sin ser proactivos. Como confiesa el profesor francés David:

Yo mismo no entiendo. No acabo de entender este país. Llevo más de veinte años estudiándolo. Cuando nació el ejército zapatista, tuve que voltear para acá. ¿Qué chingados estaba pasando? La rebelión indígena... Luego fue Chenalhó, el EPR, Atenco, la APpo, la Otra Campaña, el 132, Ayotzinapa... Una y otra vez, parecía que ahora sí iba a haber un despertar masivo... Y nada.

Este despertar masivo es precisamente lo que TeatroSinParedes y Thèatre 2 Lacte proponen cuando borran los límites entre quienes actúan y quienes pasivamente observan, entre el cuerpo colectivo y el individuo. Ambos grupos invitan al espectador a pasar por el umbral del teatro liminal que Diéguez describe como "un espacio de transformación y encuentro [que] implica cierta creencia, cierta disposición de espíritu, cierta idea de que algo ha de cambiar" (Escenarios liminales 13).

Así como David contextualiza el 68 dentro de los últimos 50 años, con la referencia a otros eventos más recientes, pero igualmente violentos y vergonzosos, TeatroSinParedes y sus colaboradores franceses descentralizan el 68 al abrir lo que Draper llama "la memoria de su temporalidad" (157). Se presenta, por ejemplo, la tortura de Bernardo antes de la escena de su activismo y su detención para que el público suponga que lo torturan durante el verano de 1968. En la escena subsecuente, la presencia de las laptops y otros objetos de la época actual sorprende al público, obligándole a reconocer que, 50 años después de Tlatelolco, sigue siendo común la aprehensión, tortura y desaparición de estudiantes activistas. Y 
peor aún, la brutal tortura de Bernardo es una señal aterradora de que las fuerzas del poder siguen eliminando del escenario político nacional a quienes se manifiestan. Auxilio no propone ser una obra sobre el 68; en cambio, se usa al 68 como una nueva manera de ver y vivir el presente para permearlo con la posibilidad del cambio.

Con esta visita guiada por el tiempo y el espacio, TeatroSinParedes y Thèatre 2 L'acte hacen que el 68 se extienda no sólo al presente, sino incluso al futuro. El melodrama, la nostalgia y la trágica historia de fondo de las obras tlatelolcas de los años 70, 80 y 90 han sido sustituidos por la indignación, el cansancio y el deseo de movilizar al público. En lugar de repetir ad nauseum "el dos de octubre no se olvida", los creadores de Auxilio incitan al público a crear un nuevo discurso político, a tomar acción y a dirigir su mirada hacia el futuro. En el programa de mano, los realizadores explican:

Nuestra intención es la de insuflar una necesaria reflexión, una mirada crítica, pero también esperanzadora sobre estos acontecimientos, a través de la estimulación de la creación colectiva, el pensamiento crítico, el arte vivo y la poesía activa. El 68 debe seguir incitándonos a cuestionar nuestro presente y a intentar construir, desde las trincheras del arte y de la imaginación creativa, posibles nuevos senderos para las generaciones actuales y futuras.

Tales reconfiguraciones artísticas del 68, explica Draper, "escriben una historia de la gesta poético-política que es el 68 desde la misma crisis de la imaginación nacional que la ocasionó" y lo "llena[n] con la posibilidad de un cambio".22

La única desventaja de la representación teatral es que, a diferencia del cine y de la fotografía, el arte escénico no sobrevive el paso del tiempo. Si bien es cierto que el pasado nunca muere, la representación teatral del mismo sufre la ironía de "morir" tan pronto como termina la obra. Como Jorge Dubatti afirma: "El teatro no preexiste ni trasciende a los cuerpos en el escenario" (Cancha con niebla 7). En el caso de Auxilio: Au Secours, el texto se compone de apenas unas páginas de monólogos poéticos y breves diálogos, mientras que el montaje es tan efímero como las memorias que conjuga, así como las emociones y pensamientos que provoca. Sin embargo, así como los recuerdos del pasado todavía subsisten en el presente, se espera que el espectáculo escénico perdure en la memoria del espectador. Aunque el 68 nunca llegue a morir, es necesario que los mexicanos, así como el Ángel de la Historia de Benjamin, se movilicen y que den la espalda a los escombros del pasado, para así poder participar colectivamente en la creación del futuro.

22 "[...] write a history of the poetic political gesture that is 1968 from within the very crisis of national imagination that it brought about" and "suffuse the present with the possibility of change". 


\section{Fuentes consultadas}

Araujo, Juan Carlos. "Auxilio". Entretenia, 23 de noviembre de 2018, www.entretenia.com/ auxilio/, consultado el 21 de mayo de 2019.

Bachelard, Gastón. La poética del espacio. Ciudad de México: Fondo de Cultura Económica, 2000.

Benjamin, Walter. “Tesis Ix”. Laboratorio de medios y humanidades, 12 de mayo de 2015, www. mediosyhumanidades.wordpress.com/2015/05/12/tesis-ix-tesis-sobre-el-concepto-de-historia-walter-benjamin-1940/, consultado el 15 de mayo de 2019.

Bert, Bruno. "Alcira o la poesía en armas. Canto al compromiso con la vida”. Tiempo Libre, 14 de febrero de 2008, www.criticateatral2021.org/html/resultado_bd.php?ID=7910, consultado el 15 de mayo de 2019.

Bixler, Jacqueline E. "Archiving Amnesia: 1968, Tlatelolco, and the Artfulness of Memory". Mexico through Art, editado por Stuart Day. Tempe: The University of Arizona Press, 2017, pp. 203-218.

Bixler, Jacqueline E. "Mexico 1968 and the Art(s) of Memory". The Long 1968, editado por Daniel Sherman, et al. Bloomington: Indiana University Press, 2013, pp. 169-215.

Bixler, Jacqueline E. "Re-membering the Past: Memory-Theatre and Tlatelolco". Latin American Research Review, vol. 37, núm. 2, 2002, pp. 119-135.

Bolaño, Roberto. Amuleto. Barcelona: Anagrama, 1999.

Diéguez, Ileana. Escenarios liminales. Teatralidades, performatividades, políticas. Ciudad de México: Paso de Gato, 2014.

Diéguez, Ileana. “№? Teatro Ojo. Escenarios y teatralidades de la memoria”. El orden invisible. Memoria de los 40 años del movimiento estudiantil del 68. Ciudad de México: UNAM, 2010, pp. 25-34.

Draper, Susana. 1968 Mexico: Constellations of Freedom and Democracy. Raleigh: Duke University Press, 2018.

Dubatti, Jorge. El convivio teatral. Teoría y práctica del teatro comparado. Buenos Aires: Atuel, 2003.

Dubatti, Jorge, editor. Cancha con niebla: teatro perdido de Ricardo Bartís. Buenos Aires: Atuel, 2003.

Faulkner, William. Requiem for a Nun. New York: Random House, 1951.

Féral, Josette y Ronald P. Bermingham. "Theatricality: The Specificity of Theatrical Language”. SubStance, vol. 31, núm. 2/3, 2002, pp. 94-108.

Guyomarch Le Roux, Sandrine. "El humor en el 'Teatro del 68”.' Tema y Variaciones de Literatura, núm. 11, 2007, pp. 105-132. 
Harmony, Olga. "El movimiento del 68 en el teatro mexicano". Tramoya, núm. 31, 1992, pp. 86-105.

Hite, Katherine. Politics and the Art of Commemoration: Memorials to Struggle in Latin America and Spain. New York: Routledge, 2013.

Lehmann, Hans-Thies. Postdramatic Theatre. Traducido por Karen Júrs-Munby, New York: Routledge, 2006.

Ontiveros, Roberto. "For Bolaño, No Divine Miracles". The Texas Observer, 10 de agosto de 2007, texasobserver.org/2567-for-bola\%EF\%BF\%BD\%EF\%BF\%BD_o-no-divine-miracles/, consultado el 15 de mayo de 2019.

Ortiz, Rubén. "La actoralidad en nuestro tiempo". Un siglo de teatro en México, editado por David Olguín. Ciudad de México: Fondo de Cultura Económica, 2011, pp. 295-315.

Poniatowska, Elena. "Otras voces y otros ecos del 68". La Jornada, 30 de noviembre de 2013, www.jornada.com.mx/2013/11/30/opinion/a04a1cul, consultado el 15 de mayo de 2019.

Poniatowska, Elena. La noche de Tlatelolco. Ciudad de México: Era, 1971.

Prieto Stambaugh, Antonio. "El puro lugar de la violencia: docufricción escénica en la ciudad de Xalapa, Veracruz". Latin American Theatre Review, vol. 52, núm. 1, 2018, pp. 125-148.

Prieto Stambaugh, Antonio. "Memorias inquietas: testimonio y confesión en el teatro performativo de México y Brasil". Corporalidades escénicas: representaciones del cuerpo en el teatro, la fanza y el performance, editado por Elka Fediuk y Antonio Prieto Stambaugh. Xalapa: Universidad Veracruzana, 2016, pp. 207-230.

Rancière, Jacques. The Emancipated Spectator. Traducido por Gregory Elliott. Brooklyn: Verso, 2009.

Sánchez, José A. "Teatralidad y disidencia”. No hay más poesía que la acción. Teatralidades expandidas y repertorios disidentes, editado por José A. Sánchez y Esther Belvis. Ciudad de México: Paso de Gato, 2015, pp. 21-58.

TeatroSinParedes y Thèatre 2 L'acte. Auxilio. Au Secours. 2018. Texto inédito. 